\title{
Análises Descritivas e Microbiológicas das Águas Minerais Envasadas e Comercializadas na Regiâo Metropolitana de Recife-PE
}

\author{
Descriptive Analyses and Microbiological of Mineral Water and Marketed in Potted \\ Metropolitan Region of Recife -PE
}

\begin{abstract}
Amanda Cristiane Gonçalves Fernandes, Lúcio Flávio Moreira Cavalcanti, Marcio Luiz Siqueira Campos Barros e Felisbela Maria Da Costa Oliveira

Universidade Federal de Pernambuco, PE, Brasil

amandafernandestt@gmail.com; flaviomat2004@hotmail.com; mlbarros@ufpe.br; felisbela.oliveira@ufpe.br
\end{abstract}

\section{Resumo}

O trabalho visa descrever a qualidade da água mineral comercializada pela população da região metropolitana de Recife-PE no ano de 2015, no que tange as análises microbiológicas e descritivas. Foram analisadas 70 amostras de sete marcas diferentes de águas minerais envasadas no periodo de Janeiro a Abril e Junho a Agosto do decorrente ano. As amostras foram divididas em trinta e cinco unidades para ambos os períodos, seguindo o Standard Methods for the Examination of Water and Wastewater, por meio dos Testes Presença e Ausência (P-A) E Pour-plate Method. Em relação às análises microbiológicas das amostras do primeiro período de acordo com a Resolução 275/2005 as marcas A, B e C tiveram suas partidas de amostras REJEITADAS e as marcas $D, E, F$ e G foram APROVADAS. No Segundo periodo as marcas A, B, C, D e E tiveram suas partidas de amostras REJEITADAS e as marcas $F$ e $G$ foram APROVADAS. O percentual apresentado no primeiro periodo indica $57,14 \%$ (APROVADAS) e 42, 85\% (REJEITADAS). No segundo periodo o percentual indica que $28,75 \%$ (APROVADAS) e 71,42\% (REJEITADAS). Ou seja, no segundo periodo obteve-se alta porcentagem de águas que foram rejeitadas devido à presença de bactérias microbiológicas.

Palavras-chave: Água Mineral; Análises Microbiológicas; Confiabilidade

\section{Abstract}

The paper aims to describe the quality of mineral water marketed by the population of the metropolitan area of RecifePE in 2015, regarding the microbiological and descriptive analyzes. We analyzed 70 samples of seven different brands of bottled mineral water in the period from January to April and June to August due year. The samples were divided into thirty-five units for both periods, according to Standard Methods for the Examination of Water and Wastewater, by means of testing the presence or absence (P-A) and Pour Plate Method. Regarding the microbiological analysis of samples of the first period in accordance with Resolution 275/2005 brands $A, B$ and $C$ had their departures REJECTED samples and the marks $D, E, F$ and $G$ were APPROVED. In the second period the marks $A, B, C, D$ and $E$ had their departures REJECTED samples and the $F$ and $G$ brands were APPROVED. The percentage shown in the first period indicates $57.14 \%$ (APPROVED) and 42, 85\% (REJECTED). In the second period the percentage indicates that $28.75 \%$ (APPROVED) and $71.42 \%$ (REJECTED). That is, in the second period there was obtained a high percentage of water which has been rejected due to the presence of microbiological bacteria.

Keywords: Mineral Water; Microbiological Analysis; Reliability 


\section{Introdução}

A má qualidade da água do abastecimento público vem trazendo insegurança e insatisfação, devido as suspeitas vinculada pela população, de várias epidemias desencadeadas pelo consumo desse produto durante anos. Sendo assim, a água mineral passou a ser adotada entre as famílias como líquido seguro e medicinal e em pouco tempo havia uma massa crescente de consumidores.

No entanto, para atender uma demanda grande, o processo de fornecimento dessas águas em sua maioria foi inesperado, e fez com que fossem geradas atividades de forma irregular: abertura de muitos poços, processo de captação incorreto e de material impróprio e rótulos alterados segundo os critérios estabelecidos pela Resolução 274/2005, acarretando a contaminação dessas águas e, consequentemente, trazendo riscos para os consumidores. Apesar dos órgãos fiscalizadores combaterem as irregularidades e evitarem alguns danos à população; a propaganda de que água mineral é um líquido livre de contaminação e impureza é muito persistente na visão dos consumidores.

A produção da água mineral na Região Metropolitana de Recife vem crescendo nos últimos anos e, economicamente, trata-se de uma das principais atividades extrativistas de minério da região (BARRETO, 2011).

Segundo BARRETO (2011 op.cit) o Estado de Pernambuco possui 45 complexos de água mineral em atividade, das quais 27 se encontram na Região Metropolitana do Recife, 6 na Zona da Mata, 11 no Agreste e uma no Sertão.

O controle estatístico das águas surge como uma proposta para adequar a qualidade da água em relação à potabilidade para o consumo humano, priorizando o consumo de água potável como forma de assegurar a saúde dos consumidores, fazendo com que esta mesmo passando por um processo de industrialização não tenha sua qualidade comprometida, através das análises quantitativas e qualitativas dos dados provenientes de análises microbiológicas das amostras de marcas disponíveis em comércio na Região Metropolitana do Recife-PE e, para isso, o trabalho utilizará a estatística descritiva imprescindível para a obtenção de resultados e relações significativas.

Sabendo-se da importância da água mineral para o consumo humano, justifica-se a realização deste trabalho ao avaliar alguns aspectos da qualidade em amostras de água mineral comercializada na Região Metropolitana do RecifePE, com avaliações de aspectos Microbiológicos segundo a Resolução 275/2005, para então obter resultados mais claros sobre a qualidade da água mineral ingerida pela população local.

\section{A água mineral}

No século XX, até o ano de 1968, a produção brasileira de água mineral engarrafada manteve-se estável, a partir daí iniciou-se uma nova fase no mercado, com o lançamento do garrafão de vidro de 20 litros, que possibilitou a ampliação do mercado. Em 1970, outra novidade do envasamento e comercialização de águas minerais, que conquistou o consumidor, foi a garrafinha plástica de polietileno de baixa densidade - PEBD. Em 1979, o crescimento do mercado aumentou ainda mais com a introdução do garrafão de 20 litros de policarbonato (MACÊDO, 2001).

Segundo o Código de Águas Minerais, Capítulo I, Disposições Preliminares, Art. 1': “águas minerais são aquelas provenientes de fontes naturais ou de fontes artificialmente captadas que possuam composição química ou propriedades físicas ou físico-químicas distintas das águas comuns, com características que lhes confiram uma ação medicamentosa". 
A exploração de água mineral no Brasil obedece ao Código de Mineração e ao Código de Águas Minerais que constituem os instrumentos básicos legais reguladores da pesquisa e da lavra dessas águas no território nacional (DNPM, 2005). A coleta deve ser realizada sob condições que garantam a manutenção das características originais da água no poço ou fonte; essas águas devem permanecer estáveis dentro dos limites de flutuação, sem influência direta de águas superficiais (BRASIL, 2006; CAC 1985).

Além da implementação de várias medidas de higiene durante a captura e embalagem da água mineral tais como saneamento dos equipamentos e cuidados no armazenamento dos materiais de embalagem, cuidados especiais devem ser tomados durante o armazenamento e transporte do produto final. As garrafas cheias devem ser armazenadas e transportadas em condições que excluam a possibilidade de contaminação e proliferação microbiana e protejam o produto e sua embalagem de danos e de deterioração (BRASIL, 2006; CAC, 1985).

\subsection{Classificações das Fontes de Água Mineral}

De acordo com o Art. 36 do Capítulo VIII do Código de Águas Minerais, as fontes de água mineral serão classificadas, além do critério químico, quanto aos gases e à temperatura.

\section{Caracteristicas microbiológicas para água mineral e água natural}

A Resolução RDC $\mathrm{n}^{\circ}$ 275, de 22 de setembro de 2005 tem como objetivo fixar as características microbiológicas para Água Mineral Natural e Água Natural. De acordo com a Tabela 1 (abaixo) as conformidades das características microbiológicas para Água Mineral Natural e Água Mineral.

Tabela 1 - Características Microbiológicas para Água Mineral Natural e Água Natural de Acordo com a Resolução $275 / 2005$

\begin{tabular}{|c|c|c|c|c|c|}
\hline Microrganismo & $\begin{array}{c}\text { Amostra } \\
\text { Indicativa } \\
\text { Limites }\end{array}$ & $\mathbf{n}$ & c & $\mathbf{m}$ & $\mathbf{M}$ \\
\hline $\begin{array}{l}\text { Escherichia coli ou coliforme (fecais) } \\
\text { termotolerantes, em } 100 \mathrm{~mL}\end{array}$ & Ausência & 5 & 0 & -- & Ausência \\
\hline Coliformes totais, em $100 \mathrm{~mL}$ & $\begin{array}{c}<1,0 \mathrm{UFC} ;<1,1 \\
\text { NMP ou ausência }\end{array}$ & 5 & 1 & $\begin{array}{c}<1,0 \mathrm{UFC} ;<1,1 \\
\text { NMP ou ausência }\end{array}$ & $\begin{array}{l}2,0 \text { UFC ou } \\
2,2 \mathrm{NMP}\end{array}$ \\
\hline Enterococos, em $100 \mathrm{~mL}$ & $\begin{array}{c}<1,0 \mathrm{UFC} ;<1,1 \\
\text { NMP ou ausência }\end{array}$ & 5 & 1 & $\begin{array}{c}<1,0 \mathrm{UFC} ;<1,1 \\
\text { NMP ou ausência }\end{array}$ & $\begin{array}{l}2,0 \text { UFC ou } \\
2,2 \mathrm{NMP}\end{array}$ \\
\hline $\begin{array}{l}\text { Pseudomonas aeruginosa, } \\
\text { em } 100 \mathrm{~mL}\end{array}$ & $\begin{array}{c}<1,0 \mathrm{UFC} ;<1,1 \\
\text { NMP ou ausência }\end{array}$ & 5 & 1 & $\begin{array}{c}<1,0 \mathrm{UFC} ;<1,1 \\
\text { NMP ou ausência }\end{array}$ & $\begin{array}{l}2,0 \text { UFC ou } \\
2,2 \mathrm{NMP}\end{array}$ \\
\hline $\begin{array}{l}\text { Clostrídios sulfito redutores ou } \\
\text { Clostridium perfringens, em } 100 \mathrm{~mL}\end{array}$ & $\begin{array}{c}<1,0 \mathrm{UFC} ;<1,1 \\
\text { NMP ou ausência }\end{array}$ & 5 & 1 & $\begin{array}{c}<1,0 \mathrm{UFC} ;<1,1 \\
\text { NMP ou ausência }\end{array}$ & $\begin{array}{l}2,0 \text { UFC ou } \\
2,2 \mathrm{NMP}\end{array}$ \\
\hline
\end{tabular}


n: é o número de unidades da amostra representativa a serem coletadas e analisadas individualmente.

c: é o número aceitável de unidades da amostra representativa que pode apresentar resultado entre os valores "m" e "M".

m: é o limite inferior (mínimo) aceitável. É o valor que separa qualidade satisfatória de qualidade marginal do produto. Valores abaixo do limite "m" são desejáveis.

M: é o limite superior (máximo) aceitável. Valores acima de "M" não são aceitos.

\section{Localização e distribuição dos complexos de água mineral}

A produção da água mineral na Região Metropolitana de Recife vem crescendo nos últimos anos e, economicamente, trata-se de uma das principais atividades extrativistas de minério da região (BARRETO, 2011).

Segundo BARRETO (2011op.cit) o Estado de Pernambuco possui 45 complexos de água mineral em atividade, das quais 27 se encontram na Região Metropolitana do Recife, 6 na Zona da Mata, 11 no Agreste e uma no Sertão. Dos 27 complexos da RMR, 13 encontram-se no município do Recife, 7 no município de Paulista, 4 no município de Camaragibe, um no município do Jaboatão dos Guararapes, um no município de Abreu e Lima e um no município do Cabo de Santo Agostinho, conforme aponta o figura 2 (abaixo).

Figura 1: Gráfico da Distribuição Percentual dos Complexos de Água Mineral na RMR.

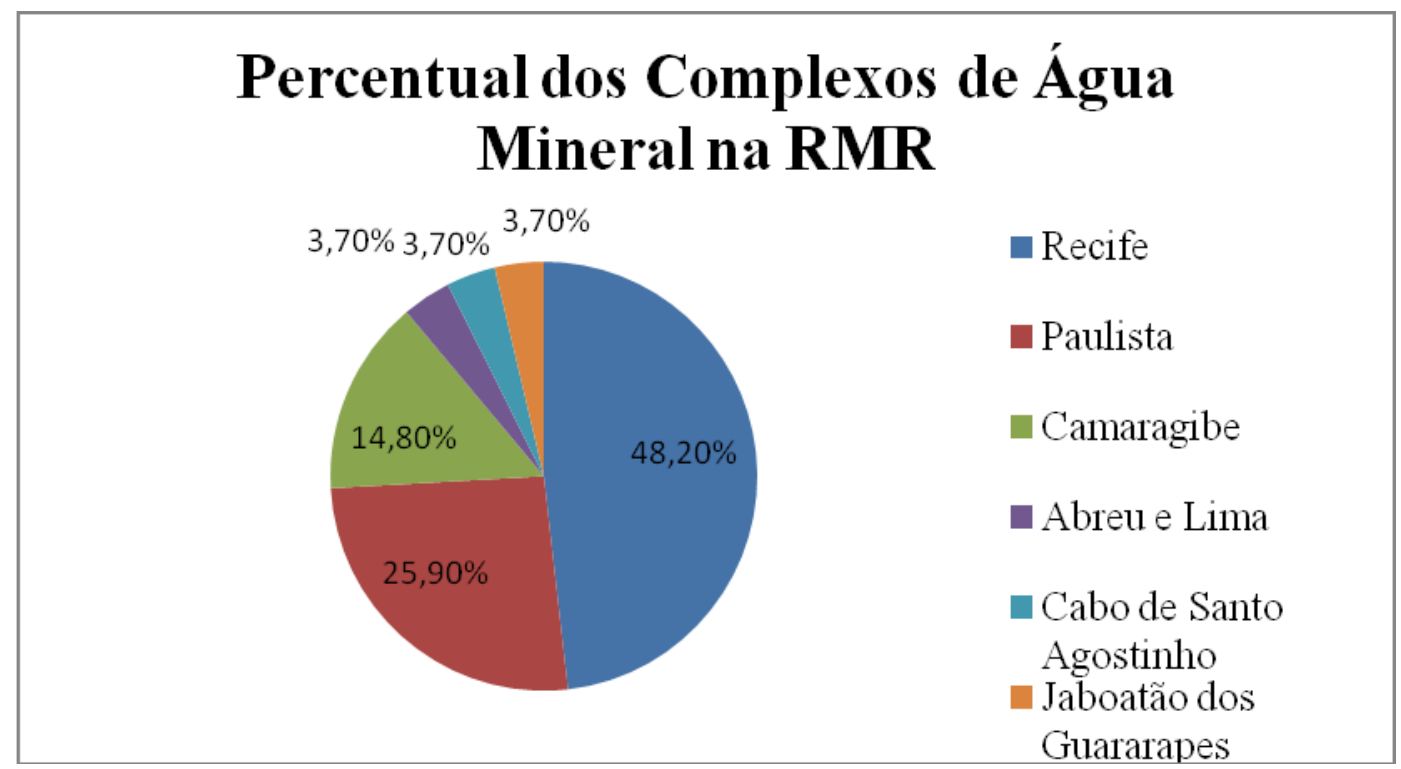

Fonte: https://www.ufpe.br/ppgeminas/images/word/2011/julio_barreto.pdf, acesso 12 de

Setembro de 2015

Portanto, devem ser realizadas periodicamente análises microbiológicas na fonte e no produto final envasado, tanto pelo produtor como pelo órgão fiscalizador. (BUZZETTI, 1998). 


\section{Microorganismos monitoredos na água mineral}

A amostra é condenada (rejeitada) quando for constatada a presença de Escherichia coli ou coliformes (fecais) termotolerantes ou quando o número de coliformes totais e ou Enterococos e ou Pseudomonas aeruginosa e ou Clostrídios Sulfito Redutores ou C. perfringens for maior que o limite estabelecido para amostra indicativa (BRASIL, 2000).

O grupo dos coliformes termotolerantes, cujo habitat geralmente é o trato intestinal do homem indica contaminação de origem ambiental e fecal do produto (MOTTA et al., 2000). A pesquisa de coliformes termotolerantes e de Escherichia colinos alimentos fornece com maior segurança informações sobre as condições sanitárias do produto e melhor indicação da eventual presença de enteropatógenoos (APHA, 2001).

Atualmente, sabe-se que o grupo dos coliformes inclui pelo menos três gêneros: Escherichia, Enterobacter e Klebsiella, dos quais incluem cepas de origem não fecal (água, solo e vegetais). Por esse motivo, a presença de coliformes termotolerantes é menos representativa, como indicação de contaminação fecal, do que a enumeração de Escherichia coli, porém muito mais significativa do que a presença de coliformes totais dadas a alta incidência de Escherichia coli no grupo fecal (SILVA et al., 2001).

A integridade física de embalagens utilizadas para o envase de água mineral deverá sofrer inspeção individual, seguida de sanificação em lavadoras específicas que devem localizar-se o mais próximo da sala de envase (ABERC, 1999).

A sanificação deve ser realizada por meios físicos ou químicos empregando-se procedimentos de eficácia comprovada. Na sanificação por meios físicos emprega-se calor (vapor; água quente) e radiação ultravioleta (Pinheiro, 1978 apud Cardoso et al., 2003), enquanto que a sanificação através de agentes químicos depende de uma série de compostos bactericidas, desde ácidos orgânicos até agentes umectantes complexos. Por questões econômicas, na prática os compostos clorados, iodados e os quartenários de amônia são os mais utilizados (ABERC, 1999).

A sanificação inadequada das embalagens ou a sua contaminação posterior resulta na condenação do lote de água mineral. Segundo o Ministério da Saúde, neste produto não podem ser constatadas as presenças de Escherichia coli. ou coliformes (fecais) termotolerantes ou coliformes totais, Enterococos, Pseudomonas Aeruginosa e/ou Clostrídios sulfito redutores, em quantidade superior a 2 UFC/mL (BRASIL, 1999).

No caso das empresas que envasam água subterrânea para o consumo, exige-se além da higiene pessoal dos funcionários, a sanificação adequada dos garrafões, instalações, máquinas e equipamentos para evitar que bactérias patogênicas afetem a qualidade da água produzida e a saúde do homem (VAITSMAN e VAITSMAN, 2005).

\subsection{Coliformes Totais}

Dentre os parâmetros utilizados para se avaliar o grau de contaminação da água, ressalta-se a pesquisa de coliformes, em que a presença desse grupo de bactérias denota que ocorreu interferência externa na água mineral, já que não fazem parte da composição natural dessa água (FARACHE FILHO e DIAS, 2008).

Em vista da dificuldade de pesquisar microrganismos patogênicos de maneira direta, devido sua sensibilidade quando em baixo número, a necessidade de procedimentos complexos e onerosos, a avaliação microbiológica da água é realizada com o emprego de bactérias coliformes (CETESB, 1991). 


\subsection{Escherichia Coli}

Cerca de 95\% dos coliformes existentes nas fezes humanas e de outros animais são de Escherichia coli e, dentre as bactérias de habitat reconhecidamente fecal, dentro do grupo dos coliformes fecais, é a mais conhecida e a mais facilmente identificada. Por isso, a enumeração direta de Escherichia coli tem se tornado muito útil (SILVA et al., 2004; CETESB, 1997).

Enterobactéria gram-negativa, aeróbia, encontrada na flora normal do íleo e do cólon do homem e dos animais. Escherichia coli é a bactéria isolada com mais frequência em microbiologia. Responsável por infecção urinária, enterite, meningite neonatal, pneumonia, septicemia hospitalar, endoftalmite, artrite séptica, endocardite, abscessos hepático e cerebral (TAVARES, 2002).

\subsection{Pseudomonas Aeruginosas}

As bactérias do gênero Pseudomonas são amplamente encontradas no ambiente, sendo consideradas bactérias oportunistas responsáveis por graves infecções (SANTOS et al., 2007).

Segundo Tavares (2002), é uma enterobactéria gram-negativa, aeróbia. Pseudomonas Aeruginosa é encontrada no solo, na água não poluída, no esgoto, no intestino dos animais, na água do mar próxima aos dejetos de esgotos ou foz de rios poluídos e inúmeros reservatórios hospitalares. Responsável por diversas infecções hospitalares em pacientes imunologicamente deprimidos, como infecção urinária.

No Brasil, a Pseudomonas tem aparecido com relativa frequência em exames bacteriológicos de águas cloradas, não cloradas e até minerais naturais (COELHO et al., 2010).

\subsection{Bactérias Heterotróficas}

A contagem de bactérias heterotróficas, genericamente definidas como microrganismos que requerem carbono orgânico como fonte de nutrientes, fornece informações sobre a qualidade bacteriológica da água de uma forma ampla. O teste inclui a detecção, inespecífica, de bactérias ou esporos de bactérias, sejam de origem fecal, componentes da flora natural da água ou resultantes da formação de biofilme no sistema de distribuição. Serviram, portanto, de indicador auxiliar da qualidade da água, ao fornecer informações adicionais sobre eventuais falhas na desinfecção, colonização e formação de biofilme no sistema de distribuição (GUERRA et al., 2006), (MINISTÉRIO DA SAÚDE, 2005).

\section{Indices pluviométricos mensais da região metopolitana de Recife no ano de 2015}

Monitoramento mensal das medições pluviométricas dos períodos analisados (Janeiro a Abril) e (Junho a Agosto) no ano de 2015. Os dados foram fornecidos pela APAC (Agência Pernambucana de Águas e Clima).

Abaixo segue o gráfico 1 do tipo linhas mostrando o quantitativo geral das médias das medições pluviométricas dos postos distribuídos em toda a Região Metropolitana de Recife-PE, nos períodos de Janeiro a Abril e Junho a Agosto do ano de 2015.

O período de Janeiro a Abril do ano de 2015 aponta índices mais baixos em relação ao período de Junho a Agosto, tendo em vista um declínio relativo ao mês de Agosto. 
Gráfico 1 - Quantitativo geral das médias pluviométricas da RMR em 2015

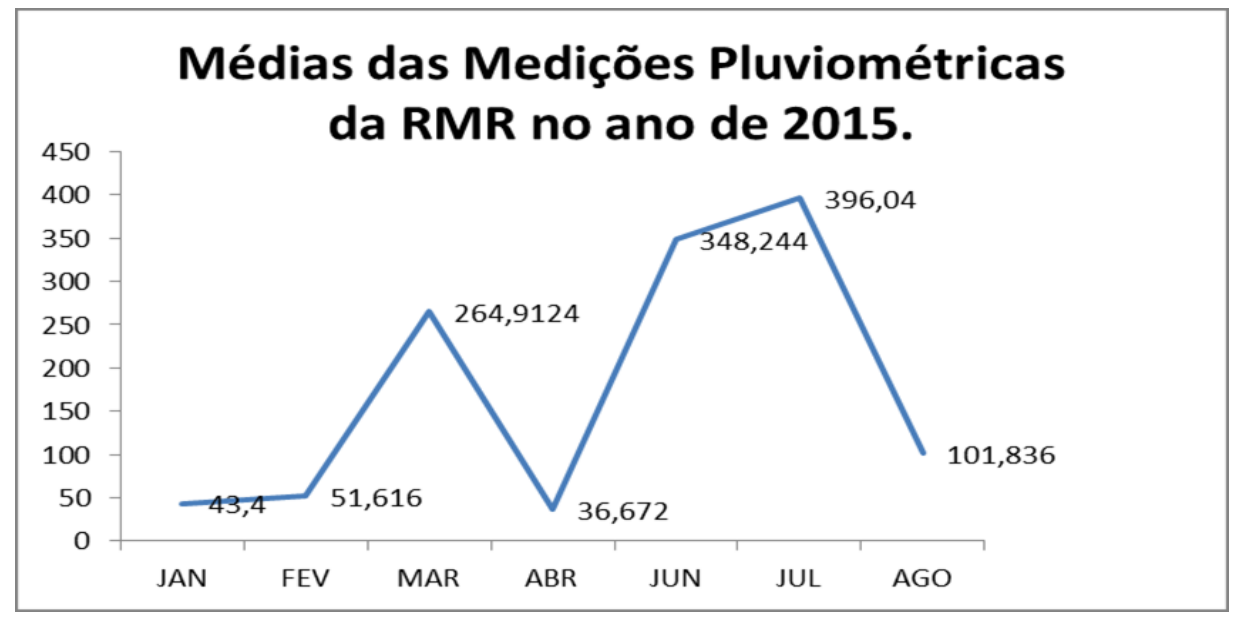

Fonte: Os autores

\section{Estatística Descritiva}

A estatística é basicamente dividida em duas partes, a primeira parte é a estatística descritiva que tem como objetivo organizar e descrever estes dados a segunda parte é a Estatística Inferencial que busca conclusões significativas para os dados.

MAROCO (2003) elenca como estatística descritiva, as medidas de tendência central; medidas de dispersão; medidas de assimetria e achatamento; medidas de associação e representação gráfica de resultados. As medidas de tendência central procuram caracterizar os valores das variáveis que ocorrem com maior frequência. Nessas medidas as estatísticas que são utilizadas com maior frequência são: média, mediana e moda. Nas medidas de dispersão, as estatísticas mais utilizadas, de acordo com autor são: o coeficiente de variação; o intervalo de variação e a amplitude interquartil. No que tange as medidas de assimetria permitem distinguir as distribuições assimétricas (média $=$ moda $=$ mediana) das distribuições assimétricas que podem ter assimetria positiva (moda $<=$ mediana $<=$ média) ou assimetria negativa (média $<=$ mediana $<=$ moda). As medidas de achatamento indicam a intensidade das frequências dos valores centrais. Por comparação com a distribuição normal cujo grau de curtose é 0,263 . Se $\mathrm{K}=0,263$ tem-se uma curva do tipo Mesocúrtica, K>0,623 a curva é do tipo Platicúrtica, K>0,623 a curva é do tipo Leptocúrtica (NETO, 2008).

\section{Materiais e Métodos}

Todas as análises foram realizadas no Laboratório de Microbiologia do Departamento de Engenharia Química da Universidade Federal de Pernambuco-UFPE.

As amostras de água mineral foram adquiridas de forma aleatória, no comércio local da Região Metropolitana do Recife-PE, através de garrafinhas envasadas e lacradas no período de Janeiro a Abril de 2015 e no período de Junho a Agosto de 2015, estas por sua vez, sem possibilidade de contaminação externa. Por se tratar de uma pesquisa sem objetivo de fiscalização julgamos desnecessário informar os nomes das marcas comerciais e empresas.

Analisou-se nesta pesquisa um total de 70 amostras de águas minerais comercializadas em garrafas envasadas e lacradas que variam entre 300 a $500 \mathrm{ml}$ para os dois períodos distintos, tendo em vista que a quantidade das amostras 
consideradas pequenas para diagnosticar com precisão a qualidade da água mineral. Para a análise microbiológica referente ao primeiro período Janeiro a Abril foram utilizadas 35 amostras, onde estas se dividiram em 7 marcas diferentes e com 5 unidades cada. Para a análise referente ao segundo período Junho a Agosto foram utilizadas 35 amostras, onde estas também se dividiram em 7 marcas diferentes e com 5 unidades cada.

A tabela 2 (abaixo) mostra as informações descritas nos rótulos para as amostras referentes ao período de Janeiro a Abril. Foram coletadas com o objetivo de possuírem o mesmo lote e foram analisadas no dia 02 de Junho de 2015. As marcas A, B e G não tinha informações no rótulo sobre o lote, além disso, a marca B não continha também a data de envase, estas por sua vez, estavam carimbadas na garrafa de forma ilegível ou parcialmente apagadas.

Tabela 2 - Amostras das Águas Minerais Coletadas nos períodos (Janeiro a Abril) do ano de 2015

\begin{tabular}{c|c|c|c|c|c}
\hline \multirow{2}{*}{ MARCA } & MI & FONTE & Município & Data de Envase & Lote \\
\hline A & $500 \mathrm{ml}$ & Seu Zeca & Recife-PE & $23 / 02 / 2015$ \\
\hline B & $500 \mathrm{ml}$ & Nino 02 & Recife-PE & Não consta no rótulo consta no rótulo & Não consta no rótulo \\
\hline C & $500 \mathrm{ml}$ & Gênesis & Paulista-PE & $20 / 04 / 2015$ & $13 / 04 / 2015$ \\
\hline D & $500 \mathrm{ml}$ & Santa Rita I & Santa Rita-PB & $04 / 01 / 2015$ & Lote L15C0165 $21: 04$ L8496801 \\
\hline E & $300 \mathrm{ml}$ & Asa Branca II & Recife-PE & Lote 1 - 19:02 P 110415 \\
\hline F & $500 \mathrm{ml}$ & São Bento & Maceió-AL & Não consta no rótulo \\
\hline G & $50 \mathrm{ml}$ & Marília -I & Recife-PE & $22 / 04 / 2015$ & .
\end{tabular}

Fonte: Dados da Pesquisa, 2015

As amostras no período de Junho a Agosto foram coletadas com o objetivo de possuírem o mesmo lote e foram analisadas em Agosto de 2015. As marcas A, B e G não tinha informações no rótulo sobre o lote, estas por sua vez, estavam contidas na garrafa de forma ilegível ou parcialmente apagadas, conforme mostra a tabela 3(abaixo):

Tabela 3 Amostras das Águas Minerais Coletadas nos períodos (Junho a Agosto) do ano de 2015

\begin{tabular}{c|c|c|c|c|c}
\hline MARCA & MI & FONTE & Município & Data de Envase & Lote \\
\hline $\mathbf{A}$ & $500 \mathrm{ml}$ & Seu Zeca & Recife-PE & $14 / 07 / 2015$ & Não consta no rótulo \\
\hline $\mathbf{B}$ & $500 \mathrm{ml}$ & Nino 02 & Recife-PE & $08 / 07 / 2015$ & Não consta no rótulo \\
\hline $\mathbf{C}$ & $500 \mathrm{ml}$ & Gênesis & Paulista-PE & $19 / 06 / 2015$ & Lote L14F1913 \\
\hline $\mathbf{D}$ & $500 \mathrm{ml}$ & Santa Rita I & Santa Rita-PB & $04 / 07 / 2015-$ ás $23: 14$ & Lote L 15C0290 \\
\hline $\mathbf{E}$ & $300 \mathrm{ml}$ & Asa Branca II & Recife-PE & $29 / 06 / 2015$ & Lote 19:41 L8534741 \\
\hline $\mathbf{F}$ & $500 \mathrm{ml}$ & São Bento & Maceió-AL & $16 / 07 / 2015$ & Lote 1 - 19:50 P 160715 \\
\hline $\mathbf{G}$ & $500 \mathrm{ml}$ & Marília $-\mathrm{I}$ & Recife-PE & $10 / 07 / 2015$ & Não consta no rótulo \\
\hline
\end{tabular}

Fonte: Dados da Pesquisa, 2015

As amostras foram analisadas seguindo o Standard Methods for the Examination of Water and Wastewater, por meio dos Testes Presença e Ausência (P-A) E Pour-plateMethod. As embalagens foram devidamente higienizadas e foram abertas conforme a metodologia padrão de análises microbiológicas, garantindo-se a não contaminação das amostras no momento das análises. 
A presença $(\mathrm{NMP} / 100 \mathrm{ml})$ de bactérias do grupo coliformes totais foi determinada por meio da Técnica de Tubos Múltiplos adaptada, utilizando-se uma série de cinco tubos para cada amostra, cultivando-se a amostra em meio caldo laurel sulfato triptose para o ensaio presuntivo e em meio caldo bile verde brilhante $2 \%$ para o ensaio confirmativo, seguindo-se as orientações determinadas pelo Standard Methods for the Examination of Water ande Wastewater.

As bactérias do grupo coliforme termo tolerantes/fecais e E. coli também foi determinada por meio da Técnica de Tubos Múltiplos adaptada, utilizando-se uma série de cinco tubos para cada amostra, cultivando-se a amostra em meio caldo EC, seguindo-se as orientações determinadas pelo Standard Methods for the Examination of Water and Wastewater.

A presença (NMP/100 ml) de P. Aeruginosas também foi determinada por meio da Técnica de tubos Múltiplos adaptada, utilizando-se uma série de cinco tubos para cada amostra, cultivando-se a amostra em meio caldo asparagina para o ensaio presuntivo e em meio caldo acetamida para o ensaio confirmativo, seguindo-se as orientações determinadas pelo Standard Methods for the Examination of Waterand Wastewater.

A contagem de bactérias heterotróficas foi determinada a partir da Técnica de Cultivo em Profundidade (Pourplate Method), utilizando-se o meio de cultura Müeller Hinton Agar (MHA), seguindo-se as orientações determinadas pelo Standard Methods for the Examination of Water and Wastewater

Como legislação base, adotou-se a Resolução RDC n 275, de 22 de Setembro de 2005, como padrão para avaliação da ausência de microrganismos do grupo Coliforme Totais, do grupo Coliforme Termo tolerantes e E. coli e Pseudomonas Aeruginosas nas amostras, pois esta legislação dispõe sobre o Regulamento Técnico de Características Microbiológicas para Água Mineral e Água Natural.

Para a Estatística Descritiva utilizou-se o programa Excel 2010 analisou a frequência relativa e porcentagem.

Abaixo segue a figura 2 que detalha o processo de análise microbiológica das Águas Minerais e Contagem de Bactérias Heterotróficas sem identificação.

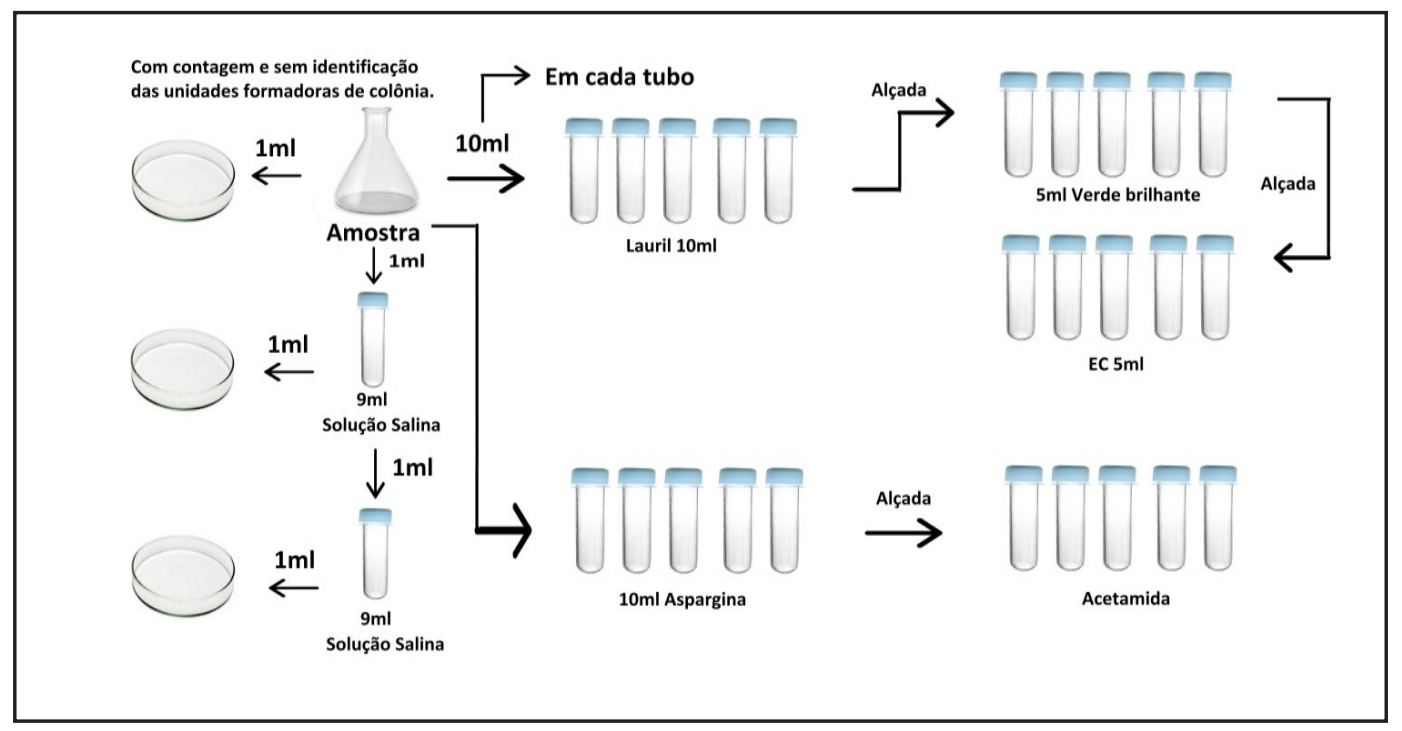

Figura 2 - Esquema para Análise Microbiológica das Águas Minerais e Contagem de Bactérias Heterotróficas sem Identificação

Fonte: Os autores (2015) 


\section{Resultados e discussão}

Em relação às análises descritivas para a variável Coliformes Totais, o gráfico 2 (abaixo) do tipo barras mostra uma porcentagem geral do quantitativo de amostras para os dois períodos analisados.

Gráfico 2 - Porcentagem Geral Referente a variável Coliformes Totais para os Dois Períodos Analisados

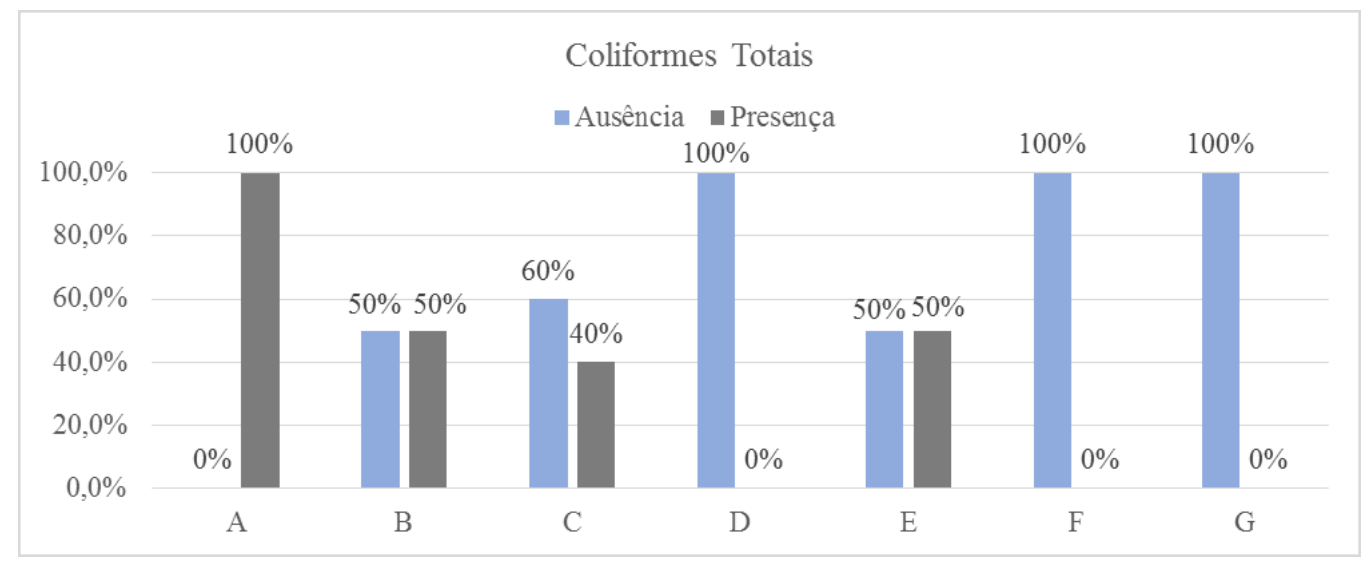

Fonte: Os autores (2015)

Em relação às análises descritivas para a variável Eschericha Coli ou C.F.T, o gráfico 3 (abaixo) do tipo barras mostra uma porcentagem geral do quantitativo de amostras para os dois períodos analisados.

Gráfico 3: Porcentagem Geral Referente a variável Eschericha Coli ou C.F.T para os Dois Períodos Analisados

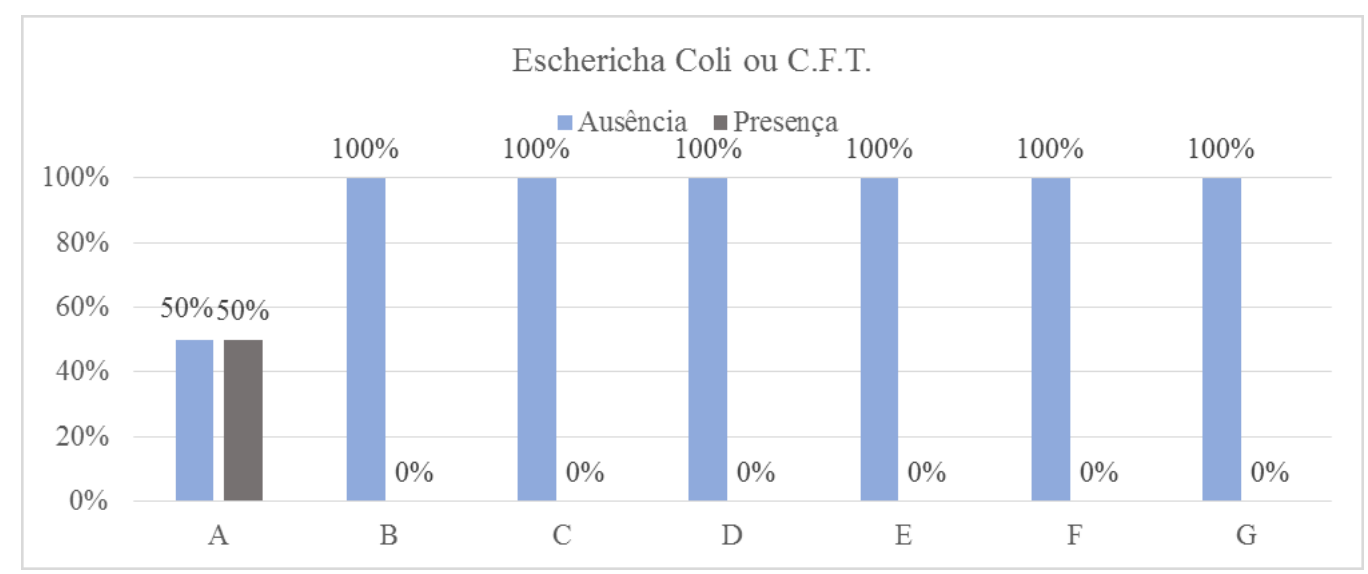

Fonte: Os autores (2015)

Em relação às análises descritivas para a variável Pseudomonas Aeruginosas, o gráfico 4 (abaixo) do tipo barras mostra uma porcentagem geral do quantitativo de amostras para os dois períodos analisados. 
Gráfico 4: Porcentagem Geral Referente a variável Pseudomonas Aeruginosas para os dois Períodos Analisados

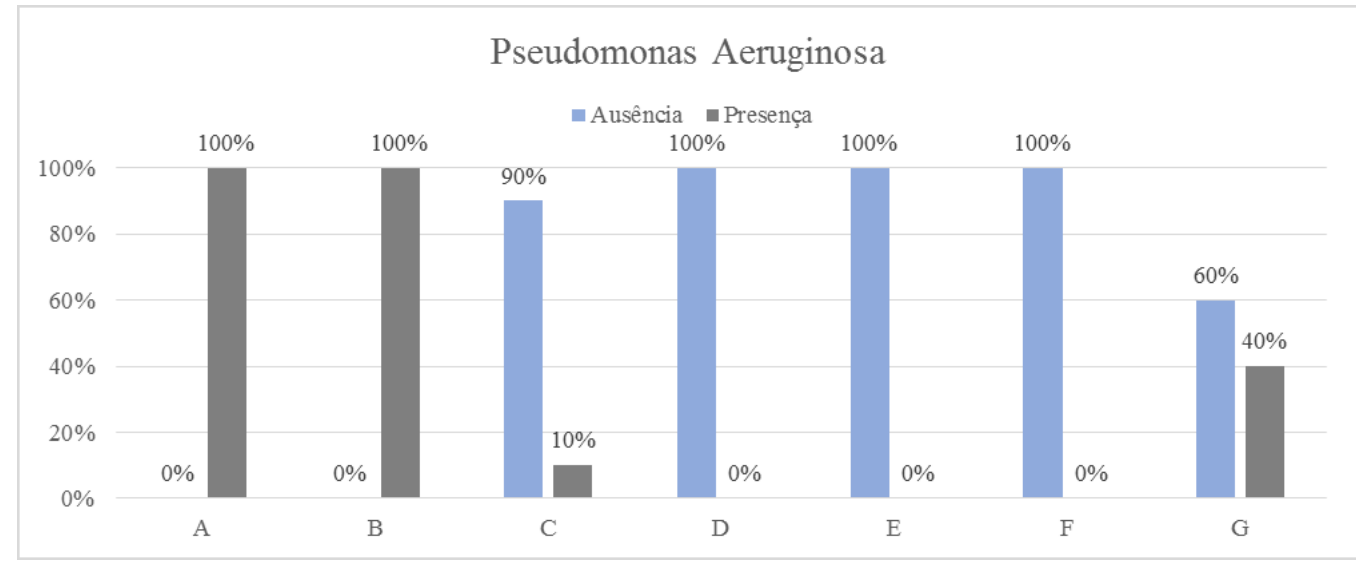

Fonte: Os autores (2015)

\section{Conclusões}

Ao compararmos os rótulos das marcas analisadas em relação às análises microbiológicas das amostras referentes ao primeiro período (Janeiro a Abril)/2015 de acordo com a Resolução 275/2005 as marcas A, B e C tiveram sua partida de amostras REJEITADAS e as marcas D, E, F e G tiveram sua partida de amostras APROVADAS. No Segundo Período (Junho a Agosto)/2015 as marcas A, B, C, D e E tiveram sua partida de amostras REJEITADAS e as marcas $\mathrm{F}$ e $\mathrm{G}$ tiveram sua partida de amostras APROVADAS. Conforme o percentual que apresenta no primeiro período 57,14\% (APROVADAS) e 42, 85\% (REJEITADAS). No segundo período 28,75\% foram (APROVADAS) e 71,42\% (REJEITADAS). Ou seja, no segundo período (Junho a Agosto)/2015 obteve -se uma alta porcentagem de águas que tiveram suas partidas de amostras rejeitas devido a presença de bactérias microbiológicas nas amostras de águas minerais analisadas conforme a Resolução 275/2005.

$\mathrm{Na}$ contagem de Bactérias Heterotróficas referentes aos períodos analisados verificaram-se através do Teste de Shapiro-Wilk que os dados não seguem uma distribuição normal; foi utilizado o teste não paramétrico Kruskal-Wallis e constatou-se que havia diferença estatisticamente significativa entre os tratamentos para o primeiro período; através da Comparação Múltipla de Médias é possível observar os tratamentos que diferem entre si: A-C, A-E, A-F, B-C e B-E; foi utilizado o teste não paramétrico Kruskal-Wallis e verificou-se que havia diferença estatisticamente significativa entre os tratamentos para o segundo período; através da Comparação Múltipla de Médias é possível observar os tratamentos que diferem entre si: B-E, B-F, C-E e C-F.

Através do Teste Qui-Quadrado foi possível analisar se existe associação entre as variáveis qualitativas (Coliformes Totais e Pseudomonas Aeruginosas), exceto Echericha Coli, pois devido ter caselas iguais a 0 , o teste quiquadrado não se aplica nesse caso. Verificou-se que não tem associação entre as variáveis qualitativas (Coliformes Totais e Pseudomonas Aeruginosas) e os períodos analisados.

Devido as amostras serem relativamente pequenas tornam-se impróprio apontar os resultados das análises microbiológicas com alto nível de confiabilidade das águas minerais comercializadas na região metropolitana de Recife, além disso, é preciso ressaltar que as embalagens que as águas foram envasadas, o manejo inadequado e o lugar de conservação pode vir a interferir na qualidade dessas águas, são possibilidades que podem vir a contribuir nesses resultados. 
Através desta pesquisa é possível desenvolver a partir da modelagem matemática a realização de simulações de cenários futuros, que podem colaborar com o processo de tomada de decisão. Além disso, utilizar a análise fatorial para os dados químicos e físicos químicos como forma de monitorar a intensidade dos compostos na água subterrânea.

Assim sendo, através dessa pesquisa tem uma melhor alternativa para que consumidores de água mineral possam analisar a qualidade do produto consumido.

\section{Referências}

APHA - AMERICAN PUBLIC HEALTH ASSOCIATION. Committee on Microbiological for Foods.Compendium of methods for the microbiological examination of foods.4.ed. Washington: American Public Health Association, 2001.

BARRETO, J.C.F. A Água Mineral na Região Metropolitana de Recife: Riscos de Contaminação dos Aquíferos. Recife -PE. Ano: 2011. Dissertação/UFPE.

BRASIL. Ministério da Saúde. Resolução n³10, de 16 de julho de 1999. Regulamento técnico referente a Padrões de Identidade e qualidade para água mineral natural e água natural. Revista Água Mineral, ago/out, 1999.

BRASIL. Ministério da Saúde. Resolução n 173, de 13 de Setembro de 2006. Dispõe sobre o Regulamento Técnico de Boas Práticas para Industrialização e Comercialização de Água Mineral Natural e de Água Natural e a Lista de Verificação das Boas Práticas para Industrialização e Comercialização de Água Mineral Natural e de Água Natural. Diário Oficial [da] República Federativa do Brasil, Brasília, DF, 14 set. 2006, Seção 1.

BRASIL. ANVISA - Agência Nacional de Vigilância Sanitária. Resolução RDC n 275, de 22 de setembro de 2005, "Regulamento Técnico de Características Microbiológicas para Água Mineral Natural e Água Natural." Brasília. 2005. Disponível em: <http://elegis. anvisa.gov.br/leisref/public/search.php>. Data: 20/11/2015.

BUZZETTI, A.R. Como montar uma empresa de água mineral. Revista Engarrafador Moderno, São Paulo, n60, p.3237, out.1998.

CETESB (Companhia Estadual de Tecnologia e Saneamento Ambiental). Controle da qualidade da água para consumo humano: bases conceituais e operacionais. São Paulo: CETESB, 1997.

CÓDIGO DE ÁGUAS MINERAIS, DECRETO-LEI No 7.841 de 08 de Agosto de 1945.

COELHO, D. L.; PIMENTEL, I. C.; BEUX, M. R. Uso do método cromogênico para quantificação do NMP de bactérias do grupo coliforme em águas minerais envasadas. Bol. CPPA, v.16, n.1, p.45-54, 1998.

DEPARTAMENTO NACIONAL DE PRODUÇÃO MINERAL-DNPM. Água mineral, 2005.Disponívelem:<http://www.dnpm.gov.br/assets/galeriadocumento/sumariomineral2005/Agua\%20Mineral\% 202005rev.doc>. Acesso em: 20 nov. 2010.

FARACHE FILHO, A.; DIAS, M. F. F. Qualidade microbiológica de águas minerais em galões de 20 litros. Alimentação e Nutrição, v. 19, n. 3, p. 243-248, 2008 . Disponível em:http://servbib.fcfar.unesp.br/seer/index.php/alimentos/article/viewFile/627/525.Acesso em: 20 de Novembro de 2015.

GUERRA, N.M.M.; OTENIO, M.H.; SILVA, M.E.Z.; GUILHERMETTI, M.; NAKAMURA, C.V.; NAKAMURA, T.U.; DIAS FILHO, B.P. Ocorrência de Pseudomonas aeruginosa em água potável. Acta Sci. Biol. Sci. 2006; 28(1): 13-18.

MACÊDO, J.A.B. Água \&Águas.1.ed. São Paulo: Livraria Varela, 2001, 503 p.

MAROCO, J. Análise estatística: com utilização do SPSS.2. ed. Lisboa: Edições Sílabo.2003.

MINISTÉRIO DA SAÚDE. Secretaria de Vigilância em Saúde (SVS), Coordenação Geral de Vigilância em Saúde Ambiental (CGVAM), Vigilância da qualidade de água para consumo humano (Vigiagua). Relatório das atividades vigiagua 1998 a 2005. 2005.

MOTTA, M. R. A.; BELMONTE, M. A.; PANETTA, J. C. Avaliação microbiológica de amostras de carne moída comercializada em supermercados da região oeste de São Paulo. Revista Higiene Alimentar, São Paulo, v.14, n. $78 / 79$, p.59-62, 2000.

NETO, Jose. Blogspot Estatística X. Estatística Descritiva. Ano:2008. 
PINHEIRO, A.J.R.; MOSQUIM, M.C.A.V.; PINHEIRO, M.I. Processamento de leite de consumo. Rio de Janeiro: CCPL - UFV, 1978.

Resolução $n^{\circ} 275$ de 22 de setembro de 2005. Diário Oficial da União; Poder Executivo 23 de setembro de 2005 www.anvisa.gov.br.

SANTOS, L. C. dos. Relatórios Técnicos período 1997-2007. Foz do Iguaçu: ITAIPU BINACIONAL, 2007(a).

SILVA, N., JUNQUEIRO, V.C.A., SILVEIRA, N.F.A. Manual de métodos de análise microbiológica de alimentos. 2 ed. São Paulo: Varela, 2001.

SILVA, N., JUNQUEIRO, V.C.A., SILVEIRA, N.F.A. Manual de métodos de análise microbiológica de água. Campinas: ITAL/Núcleo de Microbiologia, 2004.

TAVARES, J. C. Microbiologia e Farmacologia Simplificada. Rio de Janeiro: Revinter, 2002.

VAITSMAN, D. S.; VAITSMAN, M. S. Água mineral. Rio de Janeiro: Interciencia, 2005. 219p. 